\title{
Nociception and Allodynia/Hyperalgesia Induced by Intrathecal Administration of Fenvalerate
}

\author{
Junzo Kamei ${ }^{1, *}$, Mitsumasa Sasaki ${ }^{2}$, Ko Zushida ${ }^{1}$, Kayo Morita $^{1}$ and Shun-ichi Tanaka ${ }^{3}$ \\ ${ }^{\prime}$ Department of Pathophysiology \& Therapeutics, Faculty of Pharmaceutical Sciences, Hoshi University, Tokyo 142-8501, Japan \\ ${ }^{2}$ Basic Research Laboratory, HALD Inc., Yokohama 236-0003, Japan \\ ${ }^{3}$ Department of Neurobiology of Aging Laboratories, The Mount Sinai School of Medicine, New York, NY 10029-6574, USA
}

Received March 6, $2001 \quad$ Accepted April 20, 2001

\begin{abstract}
The intrathecal injection of fenvalerate, a sodium channel activator, at doses of 0.01 to $3 \mu \mathrm{g}$, dose-dependently induced the duration of a characteristic behavioral syndrome mainly consisting of reciprocal hind limb scratching directed towards caudal parts of the body and biting or licking of the hind legs in mice. Fenvalerate-induced behavior was inhibited by morphine $(1-10 \mathrm{mg} / \mathrm{kg}$, i.p.). The characteristic behavior was also inhibited by mexiletine, a sodium channel blocker; MK-801, a $N$-methyl-D-aspartate ionchannel blocker; and GR82334, a neurokinin-1-receptor antagonist. Calphostin C (3 pmol, i.t.), a protein kinase $\mathrm{C}$ inhibitor, inhibited fenvalerate-induced behavior. On the other hand, phorbol-12, 13-dibutyrate (50 pmol, i.t.), a protein kinase $\mathrm{C}$ activator, markedly enhanced the fenvalerate-induced behavior. The present results also showed that fenvalerate produced thermal allodynia and hyperalgesia in the tail-flick test. Furthermore, fenvalerate-induced thermal allodynia and hyperalgesia were inhibited by the pretreatment with calphostin C. These results suggest that the intrathecal administration of fenvalerate induces a marked nociceptive response and thermal allodynia/hyperalgesia, and they suggest that tetrodotoxin-resistant sodium channels may play an important role in this effect.
\end{abstract}

Keywords: Allodynia, Hyperalgesia, Nociception, Fenvalerate, Tetrodotoxin-resistant sodium channel

Opening of voltage-gated sodium channels causes a rapid depolarization of the membrane potential and constitutes the upstroke phase of the action potential. Most neuronal sodium channels can be blocked by tetrodotoxin (TTX) with $\mathrm{K}_{d}$ values of $1-10 \mathrm{nM}$. However, sodium channels that are resistant to the blocking action of TTX have been found in both the central and peripheral nervous systems $(1-3)$. Dorsal root ganglion neurons express a slow activating and inactivating TTX-resistant (TTX-R) sodium channel as well as a fast activating and inactivating TTX-sensitive (TTX-S) sodium channel (4 - 7). The TTX-R sodium channel is predominantly expressed in the capsaicin-sensitive small neurons of the dorsal root ganglion and appears to play an important role in nociceptive transmission $(8-13)$, and especially in allodynia and hyperalgesia (14). Furthermore, algogenic mediators such as prostaglandin, adenosine and serotonin enhance TTX-R sodium current $(15-17)$. Null mutant mice for TTX-R sodium channels show antinociception in response to noxious mechanical stimuli and

*Corresponding author. FAX: +81-3-5498-5029

E-mail: kamei@hoshi.ac.jp. a delayed development of inflammatory hyperalgesia (18). In spinal cord astrocytes, protein kinase C enhanced TTX$\mathrm{R}$ sodium channels with leftward shifts in the voltagedependence of both activation and inactivation and produced faster kinetics (19). Several studies using protein kinase $\mathrm{C} \gamma$-knockout mice (20) and diabetic animals (2123) have indicated that protein kinase $C$ may play important roles in hyperalgesia.

The pyrethroid insecticides are known to modulate the gating kinetics of neuronal sodium channels to cause repetitive discharges and membrane depolarization. In TTX-R sodium channels, fenvalerate, a type II pyrethroid, irreversibly prolongs the sodium current during depolarization and greatly augments and prolongs the tail current (24).

Considering these findings, we hypothesized that the intrathecal injection of fenvalerate may cause increased nociception and allodynia/hyperalgesia in mice. Therefore, the aim of this study was to investigate the effect of fenvalerate on nociception and allodynia/hyperalgesia in mice. We also examined the effects of an $N$-methyl-D-aspartate (NMDA)-channel antagonist, neurokinin-1 (NK-1)-receptor antagonist and sodium-channel antagonist on fenvalerate- 
induced behavioral response in order to determine its mechanisms. Furthermore, we examined the possible involvement of protein kinase $\mathrm{C}$ on fenvalerate-induced nociception and allodynia/hyperalgesia.

\section{MATERIALS AND METHODS}

\section{Animals}

Male ICR mice (Tokyo Laboratory Animals Science Co., Ltd., Tokyo) weighing about $30 \mathrm{~g}$ were used. They had free access to food and water in an animal room, which was maintained at $24 \pm 1^{\circ} \mathrm{C}$ with a 12 -h light-dark cycle. This study was carried out in accordance with the Declaration of Helsinki and/or with the guide for the care and use of laboratory animals as adopted by the committee on the care and use of laboratory animals of Hoshi University, which is accredited by the Ministry of Education, Science, Sports and Culture.

\section{Nociceptive responses}

The experiment was performed according to the method described by Hylden and Wilcox (25). Each mouse was acclimated to an acrylic observation chamber $(39 \times 26$ $\times 24 \mathrm{~cm}^{3}$ ) for at least $5 \mathrm{~min}$ before the injection of an fenvalerate. Immediately following the injection, the mice were placed in the observation chamber. The cumulative duration (s) of biting, paw licking and scratching episodes was measured for $30 \mathrm{~min}$ after the injection of fenvalerate.

\section{Thermal allodynia and hyperalgesia}

The nociceptive response was evaluated by recording the latency to withdrawal of the tail in response to several different rates of noxious skin heating as previously described (22). Briefly, the tails of mice were exposed to the focused beam of light from a 50-W projection bulb. The heat intensity was set to one of five values by adjusting the source of voltage for the bulb from 20 to $80 \mathrm{~V}$. When a withdrawal response occurred, the stimulus was terminated and the response latency was measured electronically. In the absence of a response up to a predetermined maximum latency $(30 \mathrm{~s})$, the trial was terminated to prevent tissue damage. The tail-flick latency was determined before and $60 \mathrm{~min}$ after the injection of fenvalerate. The heat intensities at $20,25,35,50,65$ and $80 \mathrm{~V}$ produced surface skin heating rates of $0.1^{\circ} \mathrm{C} / \mathrm{s}, 0.2^{\circ} \mathrm{C} / \mathrm{s}, \quad 0.4^{\circ} \mathrm{C} / \mathrm{s}, 0.9^{\circ} \mathrm{C} / \mathrm{s}$, $3.0^{\circ} \mathrm{C} / \mathrm{s}$ and $7.3^{\circ} \mathrm{C} / \mathrm{s}$, respectively.

\section{Intrathecal injection}

Intrathecal (i.t.) administration was performed following the method described by Hylden and Wilcox (26). Each i.t. injection was administered using a 30-gauge needle directly through the intact skin between the L5 and L6 vertebrae. Drugs were given in a volume of $5 \mu \mathrm{l} /$ mouse.
Drugs

Fenvalerate, calphostin $\mathrm{C}$ and phorbol-12,13-dibutyrate $(\mathrm{PDBu})$ were purchased from Calbiochem-Novabiochem Corporation (La Jolla, CA, USA). (5R,10S)-(+)-5-Methyl10,11-dihydro-5H-dibenzo[ $a, d]$ cycloheptene-5,10-imine hydrogen maleate (MK-801) and D-Pro ${ }^{9}$-[spiro- $\gamma$-lactam]Leu $^{10}$-Trp ${ }^{11}$-physalaemin(1 - 11) (GR82334) were purchased from Research Biochemical International, Natick, MA, USA. Mexiletine hydrochloride was generously supplied by Boehringer Ingelheim KG (Ingelheim, Germany). Fenvalerate was dissolved in $0.4 \%$ DMSO in saline. Calphostin $\mathrm{C}$ and $\mathrm{PDBu}$ were dissolved in $0.1 \%$ ethanol in saline. Calphostin $\mathrm{C}$ and $\mathrm{PDBu}$ were injected i.t. $60 \mathrm{~min}$ prior to the injection of fenvalerate. Morphine and mexiletine were dissolved in saline and administered i.p. $30 \mathrm{~min}$ prior to the injection of fenvalerate. MK-801 and GR82334 were dissolved in saline and administered i.t. $30 \mathrm{~min}$ prior to the injection of fenvalerate. The dose and schedule for calphostin $\mathrm{C}$ and $\mathrm{PDBu}$ in this study were determined as described previously $(27,28)$.

\section{Data analyses}

The data are expressed as means \pm S.E.M. The statistical significance of differences between groups was assessed with an analysis of variance (ANOVA) followed by the Bonferroni/Dunnett test.

\section{RESULTS}

\section{Behavioral response induced by intrathecally administered fenvalerate}

Intrathecal injection of fenvalerate elicited a characteristic behavioral syndrome mainly consisting of reciprocal hind limb scratching directed towards caudal parts of the body and biting or licking of the hind legs in mice. The behavior response induced by fenvalerate at a dose of $3 \mu \mathrm{g}$ peaked at 10 to $20 \mathrm{~min}$ and almost disappeared $30 \mathrm{~min}$ after injection. Therefore, in subsequent experiments, the mice were observed for $30 \mathrm{~min}$ after injection of fenvalerate $(3 \mu \mathrm{g})$. As shown in Fig. 1, fenvalerate at doses of 0.01 to $3 \mu \mathrm{g}$, i.t. dose-dependently enhanced the duration of these nociceptive responses. To determine whether fenvalerateinduced behavior is related to nociception, the effect of morphine on fenvalerate-induced behavior was examined. As shown in Fig. 2A, pretreatment with morphine (1, 3 and $10 \mathrm{mg} / \mathrm{kg}$ ) given i.p. dose-dependently inhibited fenvalerateinduced behavior, suggesting that the behavioral response is related to nociception.

\section{Effects of mexiletine, MK-801 and GR82334 on fenvaler- ate-induced nociceptive response}

Figure 2B shows the effect of mexiletine, a sodium channel blocker, on fenvalerate-induced behavior. Pretreatment 


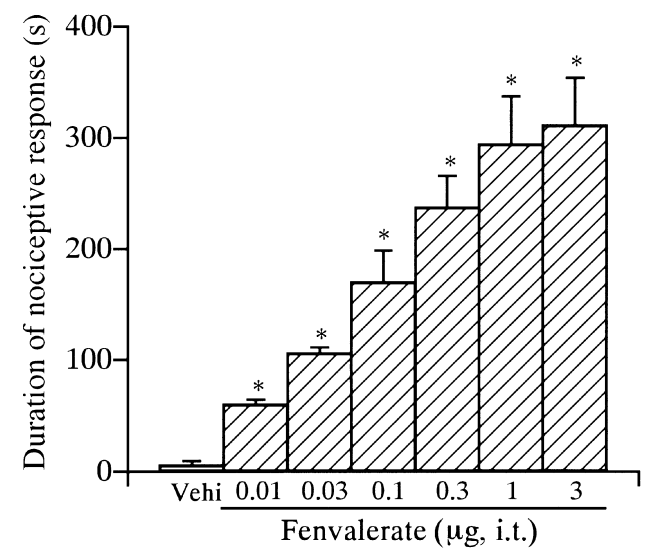

Fig. 1. Duration of the nociceptive response induced by the intrathecal administration of fenvalerate in mice. Data are expressed as the total duration of the response during the 30-min period after injection. Each column represents the mean with S.E.M. $(n=10)$. ${ }^{*} P<0.05$ vs vehicle-treated group (Vehi).

with mexiletine (10 and $30 \mathrm{mg} / \mathrm{kg}$, i.p.) dose-dependently inhibited fenvalerate-induced nociceptive behavior.

As shown in Fig. 2C, pretreatment with MK-801 (0.3$3 \mu$ g, i.t.), an NMDA channel blocker, caused a dosedependent inhibition of fenvalerate-induced nociceptive response. Furthermore, as shown in Fig. 2D, GR82334 $(0.3-3 \mu$ g, i.t. $)$, a non-peptidic NK-1-receptor antagonist, yielded results similar to that observed for MK-801.

Effects of protein kinase C modulators on fenvalerateinduced nociceptive behavior

Calphostin C (3 pmol, i.t.), a selective protein kinase C inhibitor, when administered before fenvalerate, caused a significant $(\mathrm{F}(1,55)=6.78, P<0.05)$ inhibition of fenvalerate-induced nociceptive behavior with a rightward shift of the dose-response curve for fenvalerate-induced nociceptive behavior (Fig. 3). On the other hand, PDBu (50 pmol, i.t.), a protein kinase $\mathrm{C}$ activator, significantly $(\mathrm{F}(1,56)=$ 9.60, $P<0.01)$ enhanced the fenvalerate-induced nociceptive behavior (Fig. 3). Indeed, when mice were pretreated with $\mathrm{PDBu}$, the dose-response curve for fenvalerateinduced nociceptive behavior was shifted to the left. Either calphostin $\mathrm{C}$ or $\mathrm{PDBu}$, by itself, did not produce any significant behavioral changes.

Intrathecally administered fenvalerate-induced thermal allodynia and hyperalgesia

As shown in Fig. 4, in vehicle-treated mice, the heat intensity at $35 \mathrm{~V}$ did not cause a tail-flick response within the 30-s limit. However, when the voltage of the bulb was increased to $50 \mathrm{~V}$, the mean tail-flick latency was significantly less than $30 \mathrm{~s}$. Furthermore, when the voltage was increased to 65 and $80 \mathrm{~V}$, the mean tail-flick latency decreased to approximately 8.1 and $3.3 \mathrm{~s}$, respectively. When

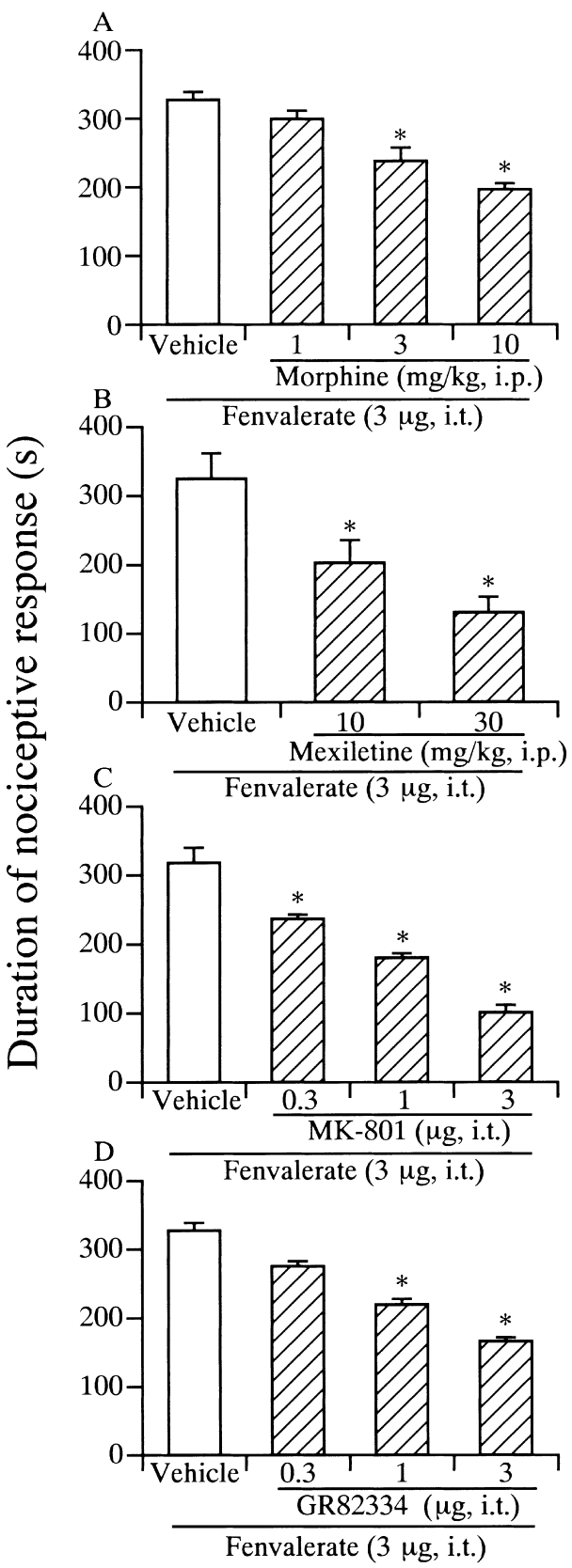

Fig. 2. Effects of morphine (A), mexiletine (B), MK-801 (C) and GR82334 (D) on the fenvalerate (3 $\mu$ g, i.t.)-induced nociceptive response in mice. Data are expressed as the total duration of the response during the 30 -min period after injection. Morphine (1, 3 and $10 \mathrm{mg} / \mathrm{kg})$ and mexiletine $(10$ and $30 \mathrm{mg} / \mathrm{kg})$ were injected i.p. $30 \mathrm{~min}$ before the injection of fenvalerate. MK-801 $(0.3,1$ and $3 \mu \mathrm{g})$ and GR82334 $(0.3,1$ and $3 \mu \mathrm{g})$ were injected i.t. $30 \mathrm{~min}$ before the injection of fenvalerate. Each column represents the mean with S.E.M. $(\mathrm{n}=10) .{ }^{*} P<0.05$ vs saline-treated group (open column).

mice were pretreated with fenvalerate, at a dose of $1 \mu \mathrm{g}$, the mean tail-flick latencies at 35, 50 and $65 \mathrm{~V}$ were significantly reduced. However, fenvalerate failed to reduce the mean tail-flick latency at $80 \mathrm{~V}$.

As shown in Fig. 4, i.t. pretreatment with calphostin C 


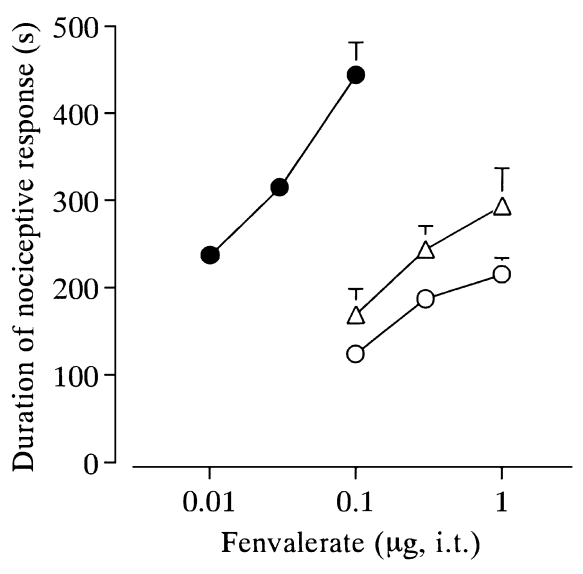

Fig. 3. Effects of i.t. administration of calphostin $\mathrm{C}$ and phorbol 12,13-dibutyrate $(\mathrm{PDBu})$ on the fenvalerate-induced nociceptive response in mice. Calphostin C (3 pmol, open circle) or PDBu (50 pmol, closed circle) was injected i.t. $60 \mathrm{~min}$ before testing. Each point or column represents the mean with S.E.M. $(\mathrm{n}=9-12)$.

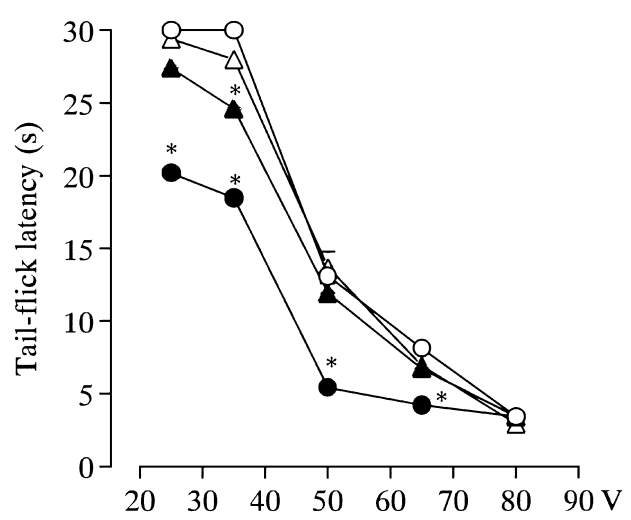

Fig. 4. Effect of calphostin $\mathrm{C}$ on the fenvalerate-induced thermal allodynia and hyperalgesia in mice. Calphostin C (10 pmol, triangles) and its vehicle (circles) were injected i.t. $60 \mathrm{~min}$ before the injection of fenvalerate. Fenvalerate $(1 \mu \mathrm{g}$, closed symbols) and its vehicle (open circle, closed circle and open triangle) were injected i.t. $60 \mathrm{~min}$ before testing. Each point represents the mean with S.E.M. for $9-10$ mice in each group. ${ }^{*} P<0.05$ vs vehicle-alone-treated group (open circle).

(10 pmol) reversed the fenvalerate-induced reduction of tail-flick latencies at 35, 50 and $65 \mathrm{~V}$. Fenvalerate-induced reduction of the tail-flick latencies at 50 and $65 \mathrm{~V}$ were not observed in calphostin C-treated mice. However, calphostin C (10 pmol), by itself, had no effect on the tailflick latencies (Fig. 4).

\section{DISCUSSION}

In the present study, we found that i.t.-administered fenvalerate produced a characteristic behavioral response mainly consisting of hind limb scratching directed towards caudal parts of the body and biting or licking of the hind legs, which peaked at 10 to $20 \mathrm{~min}$ and almost disappeared $30 \mathrm{~min}$ after injection. Pretreatment with morphine (1$10 \mathrm{mg} / \mathrm{kg}$ ) given i.p. reduced fenvalerate-induced behavior at $3 \mu \mathrm{g}$, i.t. in a dose-dependent manner. Therefore, behavior induced by fenvalerate seems to be related to nociception.

The present study also showed that fenvalerate-induced behavior was dose-dependently reduced by mexiletine (10 and $30 \mathrm{mg} / \mathrm{kg}$, i.p.), a lidocaine-like sodium channel blocker. We previously reported that mexiletine produced marked antinociception in hyperalgesia and allodynia in diabetic mice (29-31). However, since mexiletine (30 mg $/ \mathrm{kg}$, i.p.) had no significant effect on the tail-flick latency after heating the tail at $80 \mathrm{~V}$ (without mexiletine, 3.4 $\pm 0.2 \mathrm{~s}, \mathrm{n}=10$; with mexiletine, $3.9 \pm 0.2 \mathrm{~s}, \mathrm{n}=10$ ), it is possible that mexiletine by itself did not produce the antinociception in naive mice. Therefore, fenvalerate-induced behavior seems to be related to nociception caused by the activation of sodium channels. Furthermore, we also showed that MK-801, an NMDA-channel antagonist, pretreated i.t. with fenvalerate caused a dose-dependent inhibition of fenvalerate-induced nociceptive responses. Moreover, the fenvalerate-induced nociceptive response was found to be inhibited by GR82334, a non-peptidic NK-1receptor antagonist. These results lead us to suggest that fenvalerate-induced nociceptive response may be mediated through the release of glutamate and neurokinins, which caused the activation of NMDA and NK-1 receptors, by acting on the sodium channel.

The present results also showed that fenvalerate produced thermal hyperalgesia and allodynia in the tail-flick test. In vehicle-treated mice, the heat intensity at bulb voltages of 65 and $80 \mathrm{~V}$ evoked a rapid tail-flick response, whereas that at $50 \mathrm{~V}$ evoked an intermediate tail-flick latency and that at $35 \mathrm{~V}$ evoked no tail-flick response within $30 \mathrm{~s}$. In fenvalerate-treated mice, the tail-flick latency after heating the tail at 50 and $65 \mathrm{~V}$ was significantly shorter than that in vehicle-treated mice, indicating that fenvalerate-treated mice exhibit thermal hyperalgesia. In addition, a lower voltage bulb $(35 \mathrm{~V})$, which did not evoke a tail-flick response in vehicle-treated mice, did evoke a tail-flick response in fenvalerate-treated mice, indicating that fenvalerate-treated mice exhibit thermal allodynia.

A TTX-R sodium channel current appears to be primarily responsible for action potential generation in the cell body and terminals of nociceptive afferents $(32-36)$. Furthermore, nerve terminals in distal limb neuromas and skin from patients with chronic local hyperalgesia and allodynia all show marked increases in TTX-R sodium channelimmunoreactive fibers, suggesting that a TTX-R sodium channel may be related to persistent nociceptive hypersensitivity. Moreover, a TTX-R sodium channel is predominantly expressed in the capsaicin-sensitive small neurons of the dorsal root ganglion. Therefore, a TTX-R sodium 
channel appears to play an important role in nociceptive transmission $(8-13,33,35)$, and especially in allodynia and hyperalgesia (14). Based on these results, it is possible that the fenvalerate-induced nociceptive response and thermal allodynia/hyperalgesia may be mediated through the activation of TTX-R sodium channels. However, although the mode of action is different, fenvalerate is known to modulate both TTX-R and TTX-S sodium channels in a similar direction (24). Thus, it remains unclear whether TTX-R or TTX-S sodium channels are involved in the fenvalerate-induced nociceptive response and thermal allodynia/hyperalgesia. In the present study, we demonstrated that the fenvalerate-induced nociceptive response and thermal allodynia/hyperalgesia were inhibited by the pretreatment with calphostin $\mathrm{C}$, a selective protein kinase $\mathrm{C}$ inhibitor. In contrast, the fenvalerate-induced nociceptive response was enhanced when protein kinase $\mathrm{C}$ was activated by $\mathrm{PDBu}$. These results suggest that the fenvalerateinduced nociceptive response and thermal allodynia/hyperalgesia may be modulated by the protein kinase $\mathrm{C}$ activity. In this regard, Thio and Sontheimer (19) reported that the activation of protein kinase $\mathrm{C}$ by phorbol 12-myristate 13acetate had different effects on TTX-S and TTX-R sodium currents. In their paper, phorbol 12-myristate 13-acetate reduced peak TTX-S sodium currents by $25-60 \%$ and potentiated peak TTX-R sodium currents by $60-150 \%$ (19). It has also been reported that treatment with phorbol 12-myristate 13-acetate changes sodium current kinetics (19). TTX-R current activation was faster and current inactivation changed from a single- to a bi-exponential after exposure to phorbol 12-myristate 13-acetate, suggesting that protein kinase $\mathrm{C}$ phosphorylation may have activated formerly quiescent sodium channels (19). In contrast, TTX$\mathrm{S}$ current activation was unchanged, and current inactivation decreased by an average of $50 \%$ following exposure to phorbol 12-myristate 13-acetate (19). Similarly, it has been reported that the activation of protein kinase $\mathrm{C}$ increased TTX-R sodium current, whereas inhibitors of protein kinase $\mathrm{C}$ decreased TTX-R sodium current (37). Moreover, epinephrine-induced mechanical and thermal hyperalgesia, and epinephrine-induced enhancement of TTX-R sodium current in cultured rat dorsal root ganglion neurons, are reportedly inhibited by a PKC inhibitor (38). On the other hand, Scholz and Vogel (39) recently demonstrated that TTX-R sodium channel-related action potentials in dorsal root ganglion neurons were suppressed by local anesthetics, such as lidocaine and bupivacaine, in a concentrationdependent manner. In the present study, we observed that mexiletine, a lidocaine-like sodium channel blocker, inhibited the fenvalerate-induced nociceptive response. Therefore, these results and our present study strongly suggest that the activation of TTX-R sodium channels is necessary to produce a fenvalerate-induced nociceptive response and thermal allodynia/hyperalgesia.

In the present study, we observed that although the fenvalerate-induced nociceptive response was inhibited by morphine, the effective dose of morphine was relatively high. Neuropathic pain is usually difficult to treat because it includes spontaneous pain syndromes, allodynia and hyperalgesia (40). It is particularly insensitive to opioid analgesics (41). Therefore, low efficacy of morphine on fenvalerate-induced nociceptive response suggest that fenvalerate-induced nociceptive response may be a neuropathic pain model.

In conclusion, our findings indicate that the intrathecal administration of fenvalerate, a type II pyrethroid, induces a marked nociceptive response and thermal allodynia /hyperalgesia, and suggest that TTX-R sodium channels may play an important role in this effect. Furthermore, it is suggested that nociception and allodynia/hyperalgesia induced by intrathecal administration of fenvalerate might be useful for studying mechanisms and the treatment of neuropathic pain. Acknowledgments
We thank for Miss Yumi Ueda for her excellent technical assis-
tance.

\section{REFERENCES}

1 Catterall WA: Neurotoxins that act on voltage-sensitive sodium channels in excitable membranes. Annu Rev Pharmacol Toxicol 20, 15 - 43 (1980)

2 Hoehn K, Watson TW and Macvicar BA: A novel tetrodotoxininsensitive, slow sodium current in striatal and hippocampal neurons. Neuron 10, 543 - 552 (1993)

3 Yoshida S: Tetrodotoxin-resistant sodium channels. Cell Mol Neurobiol 14, 227 - 244 (1994)

4 Cotton JF and Welsh MJ: Covalent modification of the regulatory domain irreversible stimulates cystic fibrosis transmembrane conductance regulator. J Biol Chem 272, 25617 - 25622 (1997)

5 Kostyuk PG, Veselovsky NS and Tsyndrenko YA: Ionic currents in the somatic membrane of rat dorsal root ganglion neurons: I. Sodium currents. Neuroscience 6, 2423 - 2430 (1981)

6 Mclean MJ, Bennett PB and Thomas RM: Subtypes of dorsal root ganglion neurons based on different inward currents as measured by whole-cell voltage clamp. Mol Cell Biochem 80, 95 - 107 (1988)

7 Ogata $\mathrm{N}$ and Tatebayashi $\mathrm{H}$ : Kinetic analysis of two types of $\mathrm{Na}^{+}$ channels in rat dorsal root ganglia. J Physiol (Lond) 466, 9 - 37 (1993)

8 Akopian AN, Sivilotti L and Wood JN: A tetrodotoxin-resistant voltage-gated sodium channel expressed by sensory neurons. Nature 379, 257 - 262 (1996)

9 Arbuckle JB and Docherty RJ: Expression of tetrodotoxin-resistant sodium channels in capsaicin-sensitive dorsal root ganglion neurons of adult rats. Neurosci Lett 185, 70 - 73 (1995)

10 Novakovic SD, Tzoumaka E, Mcgivern JG, Haraguchi M, Sangameswaran L, Gogas KR, Eglen RM and Hunter JC: Distri- 
bution of the tetrodotoxin-resistant sodium channel PN3 in rat sensory neurons in normal and neuropathic conditions. J Neurosci 18, $2174-2187$ (1998)

11 Rabert DK, Koch BD, Ilnicka M, Obernolte RA, Naylor SL, Herman RC, Eglen RM, Hunter JC and Sangameswaran L: A tetrodotoxin-resistant voltage-gated sodium channel from human dorsal root ganglia, hPN3/SCN10A. Pain 78, $107-114$ (1998)

12 Sangameswaran L, Delgado SG, Fish LM, Koch BD, Jakeman LB, Stewart GR, Sze P, Hunter JC, Eglen RM and Herman RC: Structure and function of a novel voltage-gated tetrodotoxinresistant sodium channel specific to sensory neurons. J Biol Chem 271, 5953 - 5956 (1996)

13 Tate S, Benn S, Hick C, Trezise D, John V, Mannion RJ, Costigan M, Plumpton C, Grose D, Gladwell Z, Kendall G, Dale $\mathrm{K}$, Bountra $\mathrm{C}$ and Woolf CJ: Two sodium channels contribute to the TTX-R sodium current in primary sensory neurons. Nat Neurosci 1, 653 - 655 (1998)

14 Porecca F, Lai J, Bian D, Wegert S, Ossipov MH, Eglen RM, Kassotakis L, Novakovic S, Rabert D, Sangameswaran L and Hunter JA: Comparison of the potential role of the tetrodotoxininsensitive sodium channels, PN3/SNS and NaN/SNS2, in rat model of chronic pain. Proc Natl Acad Sci USA 96, 7640 - 7644 (1999)

15 Cardenas CG, Del Mar LP, Cooper BY and Scroggs RS: 5-HT receptors couple positively to tetrodotoxin-insensitive sodium channels in a subpopulation of capsaicin-sensitive rat sensory neurons. J Neurosci 17, 7181 - 7189 (1997)

16 England $\mathrm{S}$, Bevan $\mathrm{S}$ and Docherty RJ: $\mathrm{PGE}_{2}$ modulates the tetrodotoxin-resistant sodium current in neonatal rat dorsal root ganglion neurones via the cyclic AMP-protein kinase A cascade. J Physiol (Lond) 495, 429 - 440 (1996)

17 Gold MS, Reichling DB, Shuster MJ and Levine JD: Hyperalgesic agents increase a tetrodotoxin-resistant $\mathrm{Na}^{+}$current in nociceptors. Proc Natl Acad Sci USA 93, 1108 - 1112 (1996)

18 Akopian AN, Souslova V, England S, Okuse K, Ogata N, Ure J, Smith A, Kerr BJ, Mcmahon SB, Boyce S, Hill R, Stanfa LC, Dickenson $\mathrm{AH}$ and Wood JN: The tetrodotoxin-resistant sodium channel SNS has a specialized function in pain pathways. Nat Neurosci 2, 541 - 548 (1999)

19 Thio CL and Sontheimer H: Differential modulation of TTXsensitive and TTX-resistant $\mathrm{Na}^{+}$channels in spinal cord astrocytes following activation of protein kinase C. J Neurosci 13, 4889 - 4897 (1993)

20 Malmberg AB, Chen $\mathrm{C}$, Tonegawa $\mathrm{S}$ and Basbaum AI: Preserved acute pain and reduced neuropathic pain in mice lacking PKC $\gamma$. Science 278, 279 - 283 (1997)

21 Ahlgren SC and Levin JD: Protein kinase C inhibitors decreased hyperalgesia and C-fiber hyperexcitability in the streptozotocindiabetic rat. J Neurophysiol 72, 684 - 692 (1994)

22 Ohsawa M and Kamei J: Possible involvement of spinal protein kinase $\mathrm{C}$ in the thermal allodynia and hyperalgesia in diabetic mice. Eur J Pharmacol 372, 221 - 228 (1999)

23 Ohsawa M, Kashiwazaki T and Kamei J: Modulation of the formalin-induced nociceptive response by diabetes: possible involvement of protein kinase C. Brain Res 803, 198-203 (1998)

24 Song JH, Nagata K, Tatebayashi H and Narahashi T: Interaction of tetramethrin, fenvalerate and DDT at the sodium channel in rat dorsal root ganglion neurons. Brain Res 708, 29 - 37 (1996)

25 Hylden JLK and Wilcox GL: Intrathecal substance P elicits a caudally-directed biting and scratching behavior. Brain Res 217, 212 - 215 (1981)

26 Hylden JLK and Wilcox GL: Intrathecal morphine in mice: A new technique. Eur J Pharmacol 67, 313 - 316 (1980)

27 Narita M, Ohsawa M, Mizoguchi H, Kamei J and Tseng LF: Pretreatment with protein kinase $\mathrm{C}$ activator phorbol 12,13dibutyrate attenuates the antinociception induced by $\mu$ - but not $\varepsilon$-opioid receptor agonist in the mouse. Neuroscience 76, $291-298$ (1997)

28 Ohsawa $\mathrm{M}$ and Kamei J: Possible involvement of protein kinase $\mathrm{C}$ in the attenuation of DAMGO-induced antinociception in diabetic mice. Eur J Pharmacol 339, 27 - 31 (1997)

29 Kamei J, Hitosugi $\mathrm{H}$ and Kasuya Y: Effects of mexiletine on formalin-induced nociceptive responses in mice. Res Commun Chem Path Pharmacol 80, 153 - 162 (1993)

30 Kamei J, Hitosugi H, Kawashima N, Aoki T, Ohhashi Y and Kasuya Y: Antinociceptive effect of mexiletine in diabetic mice. Res Commun Chem Path Pharmacol 77, 245-248 (1992)

31 Kamei $\mathrm{J}$ and Zushida K: Effect of mexiletine on thermal allodynia and hyperalgesia in diabetic mice. Jpn J Pharmacol 84, $89-92(2000)$

32 Gu JG and Macdermott AB: Activation of ATP P2X receptors elicits glutamate release from sensory neuron synapses. Nature 389, 749 - 753 (1997)

33 Jeftinija S: The role of tetrodotoxin-resistant sodium channels of small primary afferent fibers. Brain Res 639, 125-134 (1994)

34 Khasar SG, Gold MS and Levine JD: A tetrodotoxin-resistant sodium current mediates inflammatory pain in the rat. Neurosci Lett 256, 17 - 20 (1998)

35 Ritter AM and Mendell IM: Somal membrane properties of physiologically identified sensory neurons in the rat: effects of nerve growth factor. J Neurophysiol 68, 2033 - 2041 (1992)

36 Strassman AM and Raymond SA: Electrophysiological evidence for tetrodotoxin-resistant sodium channels in slowly conducting dural sensory fibers. J Neurophysiol 81, 413 - 424 (1999)

37 Gold MS, Levine JD and Correa AM: Modulation of TTX-R $I_{\mathrm{Na}}$ by PKC and PKA and their role in PGE2-induced sensitization of rat sensory neurons in vitro. J Neurosci 18, $10345-$ 10355 (1998)

38 Khasar SG, Lin YH, Martin A, Gadgar J, Mcmahon T, Wang D, Hundle B, Aley KO, Isenberg W, Mccarter G, Green PG, Hodge CW, Levine JD and Messing RO: A novel nociceptor signaling pathway revealed in protein kinase $\mathrm{C}$ epsilon mutant mice. Neuron 24, $253-260$ (1990)

39 Scholz A and Vogel W: Tetrodotoxin-resistant action potentials in dorsal ganglion neurons are blocked by local anesthetics. Pain 47, 47 - 52 (2000)

40 Tasker RR, DeCarvalho GT and Dolan EJ: Intractable pain of spinal cord origin: clinical features and implications for surgery. J Neurosurg 77, 373 - 378 (1992)

41 Portenoy GN, Foley KM and Inturrisi C: The nature of opioid responsiveness and its implication for neuropathic pain: new hypotheses derived from studies of opioid infusions. Pain 43, $273-286(1990)$ 